\title{
Measurement and Calculation of Explosion Pressure for Hydroxyl Hydrocarbons Mixture Substituted
}

\author{
Jan Skř́nský1,* \\ ${ }^{1}$ Energy Research Centre, VSB-TU Ostrava, 70833 Ostrava - Poruba, Czech Republic
}

\begin{abstract}
Methanol as a biofuel requires information about the explosion parameters measured in air under various conditions in different volumes. Forty explosion pressures owing to the methanol-air mixture have been measured in the temperature range $298-423 \mathrm{~K}$ between $\Phi=0.65-2.65$ in $1 \mathrm{~m}^{3}$ explosion chamber. This work supports the systematic investigation owing to $0.005 \mathrm{~m}^{3}$ and $0.020 \mathrm{~m}^{3}$ volumes.
\end{abstract}

\section{Introduction}

Today, usually fossil fuels are used for fuel production. The reserves of these fossil-based fuels are being rapidly depleted. Besides that, when these fuels are used in internal combustion engines, they produce air pollutants such as $\mathrm{CO}, \mathrm{HC}, \mathrm{NO}_{\mathrm{x}}$ and particulate matter. Alternative sources of energy are needed in order to replace the non-renewable resources and to improve air quality [1]. Fundamental combustion research can help the clean and efficient utilization of alcohols. Lower alcohols $(\leq \mathrm{C} 4)$ with high octane number and relatively low cost have been successful in the practical use as the gasoline additives. However, low alcohols still have their disadvantages such as low energy content and high hygroscopicity and corrosivity. While, higher alcohols $(\geq \mathrm{C} 5)$ have disadvantage in poor ignition [2].

It has been well established that studies concentrated on the low alcohols (ethanol, 1butanol, 1-pentanol, 2-pentanol and 3-pentanol) in small stainless cylinder vessel with a diameter of $180 \mathrm{~mm}$ and length of $210 \mathrm{~mm}$ [3]. An experimental study of the explosive combustion of methanol-air mixtures at various initial conditions (temperatures, pressures and fuel/air ratios within the explosion limits) was performed in a small $0.005 \mathrm{~m}^{3}$ spherical stainless steel with central ignition [4]. The most recent study determined the maximum explosion pressures, the maximum rates of pressure rise, the severity factors and the maximum explosion delay time in two spherical vessels (volume: $0.005 \mathrm{~m}^{3}$ and $0.020 \mathrm{~m}^{3}$ ) for various ethanol/air mixtures $(3.5-20.0 \mathrm{vol} \%)$ at various initial pressures (10.1 $101 \mathrm{kPa})$ and temperatures $(298-373 \mathrm{~K})$ [5]. In the present preliminary study, explosion severity indices of the methanol, $\mathrm{CH}_{4} \mathrm{O}$, have been measured in the temperature range 298 $423 \mathrm{~K}$ and over stoichiometric concentrations $0.65-2.65$, in $1 \mathrm{~m}^{3}$ chamber, respectively.

\footnotetext{
*Corresponding author: jan.skrinsky@,vsb.cz
} 


\section{Experiment}

Two experimental setups have been used in the present study. One employed $1 \mathrm{~m}^{3}$ chamber located in Energy Research Centre, VSB-TU Ostrava to record explosion severity indices. Measurements of the ultra-high speed digital images were obtained using high-speed camera from the Faculty of safety engineering, VSB-TU Ostrava.

\subsection{High-speed camera}

The high-speed camera Photron FASTCAM SA-Z (speed > 1M fps; resolution > 12k fps) has been used to capture high-resolution digital images at ultra-high speeds. The high-speed camera has been installed in a chamber opening and focused on ignition source. FASTCAM Viewer tools allow image calibration and measurement of angles and distances from explosion image data. Schematic representation of the camera and the whole system is shown at Figure 1.

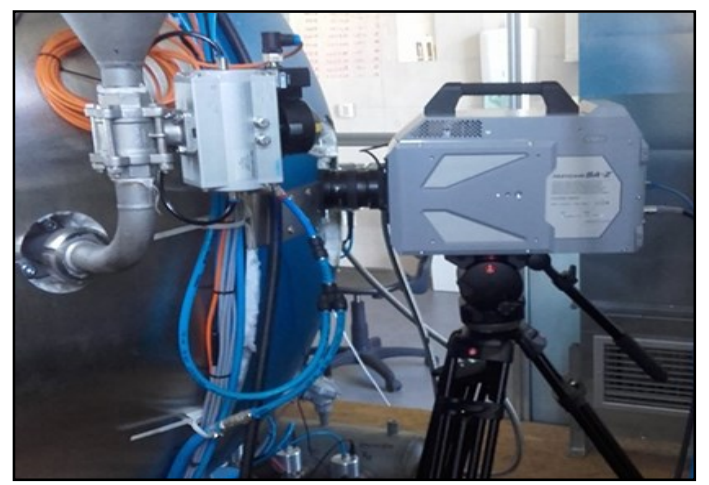

Fig. 1. High-speed camera system.

\subsection{Explosion}

Experiments were done in $1 \mathrm{~m}^{3}$ chamber made by OZM Research in accordance with EN 1839:2013 and EN 15967:2012standards [6, 7]. The chamber is a vessel of a spherical shape with an inside diameter of $1240 \mathrm{~mm}$. The vessel is provided with an opening of an inside diameter of $800 \mathrm{~mm}$, which is provided with a flange and a lock for locking the door. The material and components comply with the use of equipment for experiments at atmospheric initial pressure and initial laboratory temperature $\left(15-200{ }^{\circ} \mathrm{C}\right)$. There is one liquid dispersion system installed at the chamber. The system consists of a liquid reservoir with a capacity of $0.3 \mathrm{dm}^{3}$. Reservoir is designed for operating pressure up to $0.5 \mathrm{MPa}$ and testing pressure $10 \mathrm{MPa}$. Length of the reservoir to its diameter is 3 to 1 . The reservoir is equipped with a lid, which allows for pouring the sample liquid by syringe. Special dispersion nozzle and homogenisation were used for all experiments. The reservoir is equipped by pneumatic valve for pressurization and by remote pressure sensor for control of dispersing pressure. Reservoir's installation contains also manual ball valve for manual release of overpressure from the reservoir in case of system malfunction. The explosion chamber is equipped with measurement of time depended dynamic pressure using two pressure sensors by Kistler type 701A calibrated for the range up to $2.5 \mathrm{MPa}$. Natural frequency of the sensor is $70 \mathrm{kHz}$. Data are recorded be four-channel data card with a sampling rate $50 \mathrm{kS} / \mathrm{s} / \mathrm{channel}$. PLC Siemens Simatic 1215 connected to PC used as a user interface automatically control whole procedure including fast acting valve timing. 
Electric discharge was used as ignition source [8]. The whole system is schematically introduced at Figure 2.

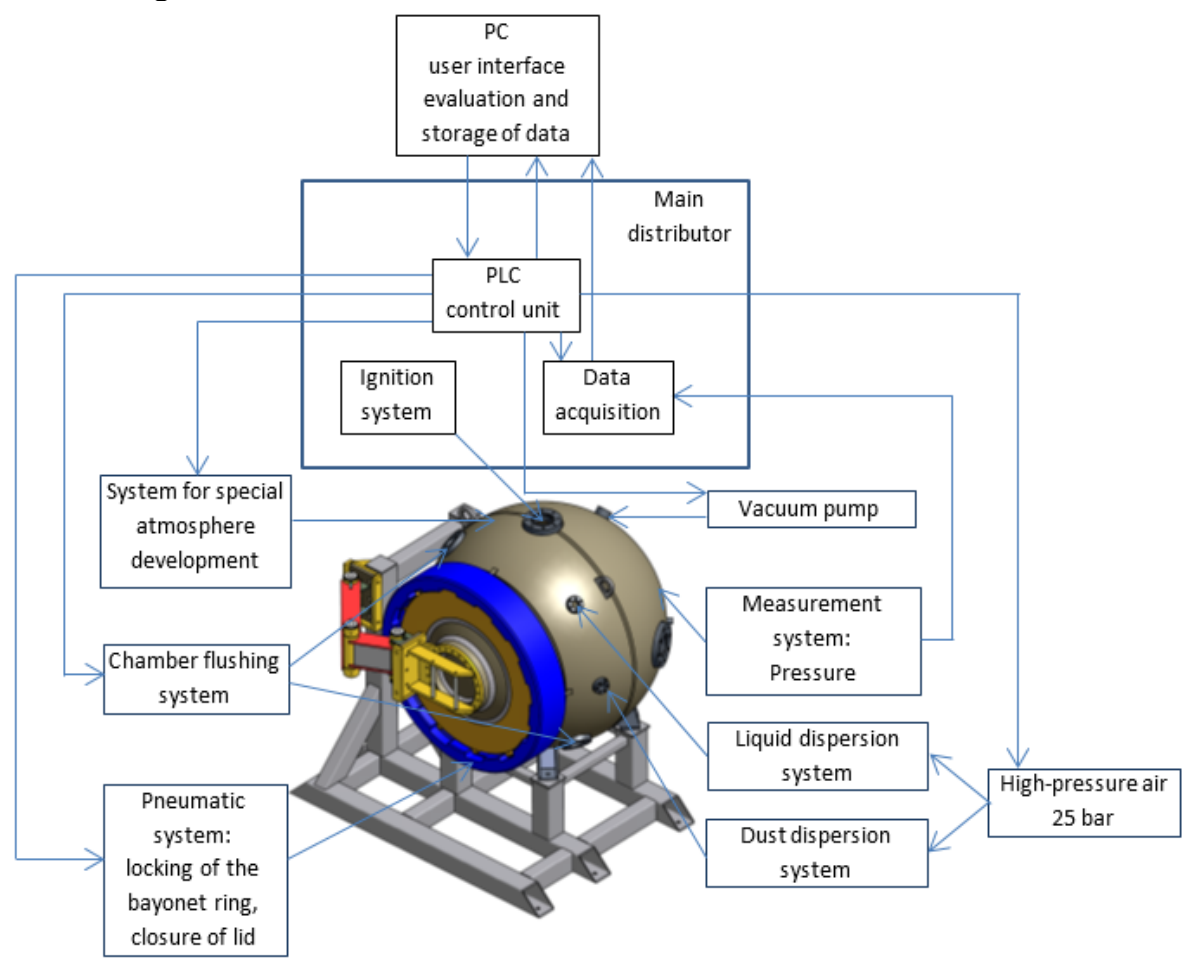

Fig. 2. Experimental set-up for liquid-air explosion parameters measurement.

\subsection{Procedure}

Procedure for vapour explosion starts with evacuation to pressure less than 0.89 bar to leave a space for the vapour. For example, the use of methanol concentrations of 5 vol. $\%$ and 10 vol. \% require the partial pressures of methane to be added are 0.05 bar and $0.10 \mathrm{bar}$ respectively. Then the evacuation pressures should be 0.84 bar and 0.79 bar respectively. PLC starts the experiment where $600 \mathrm{~ms}$ is counted as ignition delay time, and then the gas is mixed by blowing dispersion air into the methanol-air mixture inside the chamber. After that the mixture is ignited by the electric discharge. The explosion indices are measured and calculated [8].

\section{Predictions}

Method used for calculating equilibrium compositions at a specified temperature based on the minimisation of free energy technique (NASA method). The detail description of the equations and computer program for computations involving chemical equilibria in complex systems is given in [9]. These calculations provide us with the predictions for experiments at a defined temperature and constant volume for assigned thermodynamic states. The calculations considers condensed species as well as gaseous species. This approach represents ideal deflagrations in closed systems and gives the highest possible attainable explosion pressures. The present numerical method allows the 
determination of the most conservative values of adiabatic pressures and were used as suitable for prediction of measured experimental data.

\section{Results}

\subsection{High-speed images}

Figure 3 illustrates the real non-adiabatic explosion. Figure 3 illustrates the nearly laminar spherical flame that have been produced during the explosion. Beyond in hundreds of $\mathrm{ms}$ the spherical flame became turbulent and the flame speed increases monotonically with increasing turbulences and fuel air mixing.
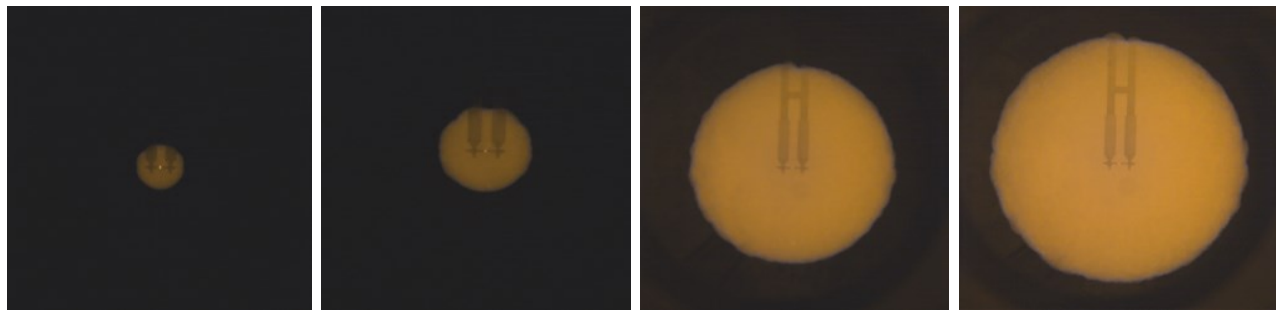

Fig. 3. High-speed images of methanol -air spherical flames $\left(\mathrm{T}_{0}=298 \mathrm{~K}, \Phi=1.15, \mathrm{P}_{0}=0.1 \mathrm{MPa}\right)$.

\subsection{Explosion indices}

The results are very similar to the our recent gas-air investigation published in $[10,11]$ with exception in $298 \mathrm{~K}$. Figure 4 is a plot of the normalized peak explosion pressure, $\mathrm{P}_{\mathrm{ex}} / \mathrm{P}_{0}$, and adiabatic explosion pressure, $\mathrm{Pad}$, versus equivalence ratio at atmospheric pressure and four initial temperatures. The $\mathrm{P}_{\mathrm{ex}} / \mathrm{P}_{0}$ explosion pressure has the maximum value of explosion pressure, at $\Phi=1.15$ as indicated in Figure 4. With the increase of temperature, the peak explosion pressure is decreased due to the decrease of the total fuel mass in gas/vapour cloud (turbulences) and shifted to the fuel rich region. This is because the species in flames at elevated temperatures are more reactive and taking into account the effect of density (point concentrations) and soot's formation combined with the wall effect. The adiabatic explosion pressure, $\mathrm{P}_{\mathrm{ad}} / \mathrm{P}_{0}$, gives the peak value around $\Phi=1.0$.

Leaner or richer mixtures make the drop of pressure between the real and adiabatic pressure. The reason is, that the real combustion is not under the absolute adiabatic conditions. With the mixture becoming richer, more soot formed in the flame, causing larger difference between $\mathrm{P}_{\mathrm{ad}} / \mathrm{P}_{0}$ and $\mathrm{P}_{\mathrm{ex}} / \mathrm{P}_{0}$. This is in agreement with [3].

As shown in Figure 5, (dP/dt) ex and $\mathrm{K}_{\mathrm{G}}$ give an approximate value at varied initial temperatures, indicating that $(\mathrm{dP} / \mathrm{dt})_{\mathrm{ex}}$ and $\mathrm{K}_{\mathrm{G}}$ are sensitive to the variation of temperature. Rate of pressure rise is affected by both flame speed and heat release (turbulences). Flame speed increases monotonically with the increase of temperature, but the decrease of total fuel mass results in the decreased heat release and offsets the effect of flame speed on the explosion pressure.

The main result is the behaviour of the vapour-air mixture bellow the Antoine's limit, i.e. saturated vapour pressure. These correlations describing the relation between vapour pressure and temperature for pure components limit the evaporation rate of methanol. For methanol is saturated vapour pressure at $298 \mathrm{~K}$ equal to 0.167837 bar [12]. It is not possible to evaporate more methanol under the given temperature and pressure conditions. Therefore, the $\mathrm{P}_{\mathrm{ex}} / \mathrm{P}_{0}$, became constant. To overcome the 16.0 vol. \% limit we have to 
increase the temperature up to $338 \mathrm{~K}$ at which is the saturated vapour pressure equal to 1.02432 bar. Both, $298 \mathrm{~K}$ (over 16.0 vol. \%) and $323 \mathrm{~K}$ (over 55.0 vol. \%) real $\mathrm{P}_{\mathrm{ex}} / \mathrm{P}_{0}$, $(\mathrm{dP} / \mathrm{dt})_{\mathrm{ex}}$ and $\mathrm{K}_{\mathrm{G}}$ values are affected by this limit.

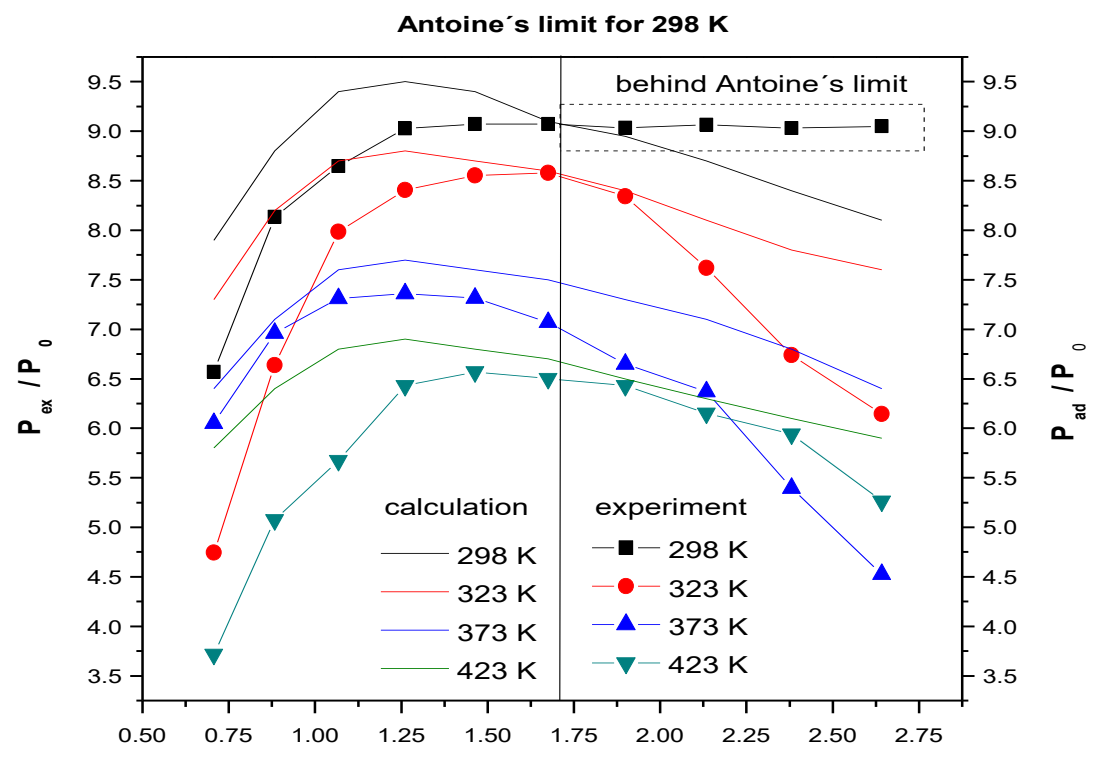

Equivalence ratio / -

Fig. 4. $\mathrm{P}_{\mathrm{ex}} / \mathrm{P}_{0}$ and $\mathrm{P}_{\mathrm{ad}} / \mathrm{P}_{0}$ at $\Phi=0.65-2.65, \mathrm{P}_{0}=0.1 \mathrm{MPa}$ and $\mathrm{T}_{0}=298-423 \mathrm{~K}$ for methanol-air mixtures.

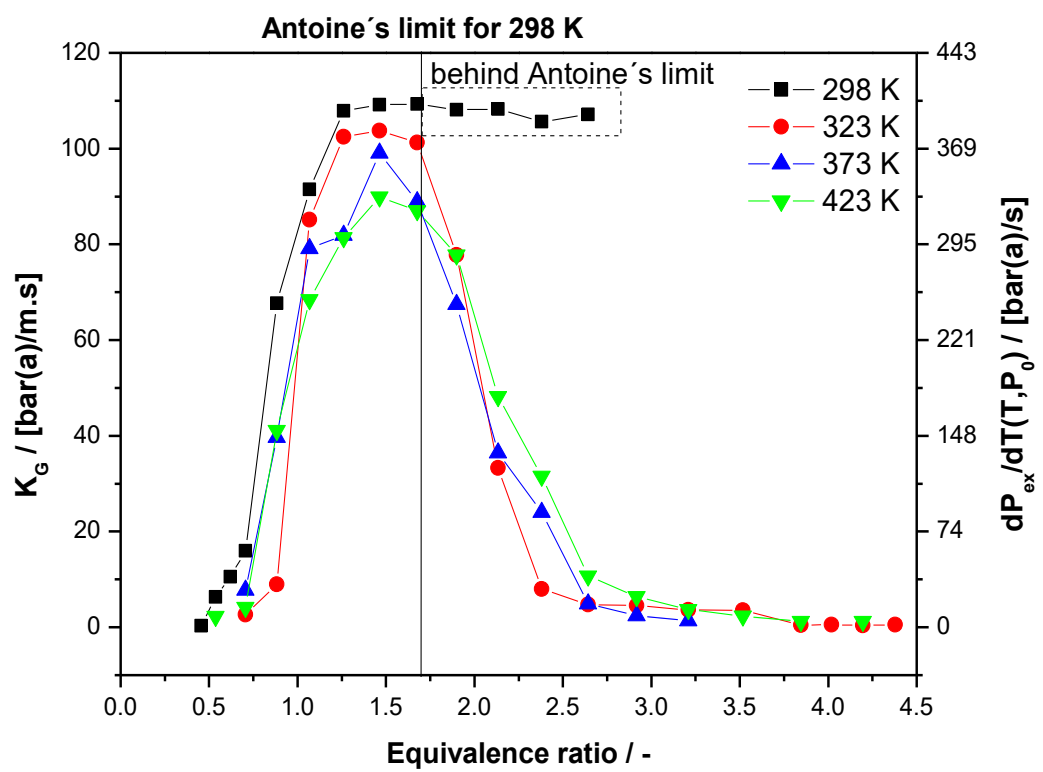

Fig. 5. $(\mathrm{dP} / \mathrm{dt}) \mathrm{ex}$ and $\mathrm{K}_{\mathrm{G}}$ at $\Phi=0.65-2.65, \mathrm{P}_{0}=0.1 \mathrm{MPa}$ and $\mathrm{T}_{0}=298-423 \mathrm{~K}$ for methanol-air mixtures. 


\section{Conclusion}

Explosion indices data are essential for a quantitative risk assessment of explosion hazard associated with the use of methanol gas. The present work is the preliminary study to investigate the influence of various initial temperatures and stoichiometric concentrations on explosion characteristics of methanol/air mixtures.

The explosion pressure, the maximum rate of pressure rise and the deflagration index are the fundamental explosion characteristics. We have described, that they have decreased with the increase of initial temperature. In all cases, the turbulent gas flow and point concentrations play crucial role in the promotion of the whole reactions due to fuel air mixing and hence the faster flame speed, and heat release.

The effect of saturated vapour pressure has been characterized in the gas phase and has been applied for methanol vapour in thermodynamic equilibrium with its condensed phases for given temperature in a closed system.

This work started a systematic comparison among the $\mathrm{C}_{n} \mathrm{H}_{2 n+2} \mathrm{O}$ analogues (where $\mathrm{n}=1$ 5) carried out in heated $1 \mathrm{~m}^{3}$ explosion apparatus built by OZM Research s.r.o. at Energy Research Centre, VŠB - Technical University of Ostrava.

This work was prepared within the project „Innovation for Efficiency and Environment - Growth“, identification code LO1403 with the financial support from the Ministry of Education, Youth and Sports in the framework of the National Sustainability Programme I. J.S. is thanked P. Lepik for providing the high-speed camera and B. Janovsky for helpful discussions about Antoine's.

\section{References}

1. $\quad$ M.B. Çelik, B. Özdalyan, F. Alkan, Fuel, 90, 1591-1598 (2011)

2. J. Skrinsky, J. Veres, V. Peer, P. Friedel, AIP Conference Proceedings, 1745, art. no. 020057 (2016)

3. Q. Li, Y. Cheng, Z. Huang, Journal of Loss Prevention in the Process Industries, 37, 91-100 (2015)

4. M. Mittu, E. Brandes, Fuel, 158, 217-223 (2015)

5. M. Mittu, E. Brandes, Fuel, 203, 460-468 (2017)

6. EN 1839:2013. Determination of explosion limits of gases and vapors. Berlin: Beuth Verlag (2013)

7. EN 15967:2012. Determination of maximum explosion pressure and the maximum rate of pressure rise of gases and vapours. Berlin: Beuth Verlag (2012)

8. B. Janovsky, J. Skrinsky, J. Cupak, J. Veres, Draft-paper in 12th International Symposium on Hazards, Prevention and Mitigation of Industrial Explosions Kansas City, USA - August 12-17 (2018)

9. S. Gordon, B.J. McBride, Computer program for calculation of complex chemical equilibrium compositions and applications, NASA Reference Publication 1311

10. J. Skrinsky, WSEAS Transactions on Environment and Development, 13, 421-430 (2017)

11. J. Skrinsky, J. Veres, J. Travnickova, Materials Science Forum, 844, 65-72 (2016)

12. DDBST Dortmund Data Bank Software \& Separation Technology GmbH, DDB Explorer Version (2015) 